\title{
Anaerobic Membrane Bioreactors (AnMBR) for Wastewater Treatment
}

\author{
Sheng Chang \\ School of Engineering, University of Guelph, Guelph, Canada \\ Email: schang01@uoguelph.ca
}

Received October 2, 2013; revised November 2, 2013; accepted November 9, 2013

Copyright (c) 2014 Sheng Chang. This is an open access article distributed under the Creative Commons Attribution License, which permits unrestricted use, distribution, and reproduction in any medium, provided the original work is properly cited. In accordance of the Creative Commons Attribution License all Copyrights (C) 2014 are reserved for SCIRP and the owner of the intellectual property Sheng Chang. All Copyright (c) 2014 are guarded by law and by SCIRP as a guardian.

\section{ABSTRACT}

This paper focuses on the recent research in the development of anaerobic membrane bioreactors in wastewater treatment. Anaerobic wastewater treatment technology is gaining increasing attention due to its capacity to convert wastewater BODs to usable biogas with relatively low energy consumption. The anaerobic membrane bioreactor (AnMBR), which is a combination of the anaerobic biological wastewater treatment process and membrane filtration, represents a recent development in the high-rate anaerobic bioreactors. This paper reviews applications and performances of AnMBR and the membrane filtration behaviour in AnMBRs.

\section{KEYWORDS}

Anaerobic Membrane Bioreactor; Wastewater Treatment; Membrane Fouling; Energy Recovery; Membrane Bioreactor

\section{Introduction}

Environmental sustainability is one of the most critical challenges that we are currently facing. To maintain a sustainable environment requires effective and advanced waste and wastewater management technologies which should not only remove the contaminants, but also be of high energy efficiency with the capacity to recover useful resources from waste and wastewater. One of the technologies to meet such requirements is the anaerobic digestion which can convert the waste BOD to usable biogas, reserve useful nitrogen and phosphorus for further recovery, and require minimum energy to operate. However, the efficiency of anaerobic digestion has been largely limited by the intrinsic slow growth rate of the anaerobic microorganisms, which results in a large reactor volume necessary for wastewater treatment by anaerobic digestion. One of the advanced solutions to improve the efficiency of anaerobic treatment is to integrate anaerobic wastewater treatment reactor with membrane filtration process to form an anaerobic membrane bioreactor system. In this system, the membrane filtration process can separate the treated wastewater from the anaerobic biomass and, at the same time, concentrate the biomass concentration in the anaerobic bioreactor to a desired level.

Although the concept of AnMBR was developed in 1980s [1], applications of the anaerobic membrane technology have been limited by concerns on the membrane fouling in the anaerobic environment, the energy consumption of the membrane processes, and the pre-matured large-scale wastewater treatment membrane filtration technology. However, with the success of MBR technology in recent years, the large-scale membrane filtration systems have become a proved technology with effective strategies for the membrane process design, operation, and maintenance developed for the biological wastewater treatment applications. These progresses and the potential of the AnMBR as an energy recovery technology have stimulated increased research interests in AnMBRs. This paper reviews the current status and recent development.

\section{AnMBR Systems}

The anaerobic membrane bioreactor is an integrated system of the anaerobic bioreactor and the low pressure ultrafiltration or microfiltration membrane filtration. Since MF/UF membranes can physically retain suspended sol- 
ids, including suspended biomass and inert solids, the AnMBR can achieve complete separation of the solid retention time from the hydraulic retention time, independent of the wastewater characteristics, biological process conditions, and the sludge properties. As shown in Figure 1, the membrane filtration can be integrated with anaerobic bioreactors in three different forms: the internal submerged membrane filtration (A), the external submerged membrane filtration (B), and the external crossflow membrane filtration (C). The anaerobic bioreactor can be the complete mix [2], the up-flow anaerobic sludge blank (UASB) [3], the expanded granular sludge

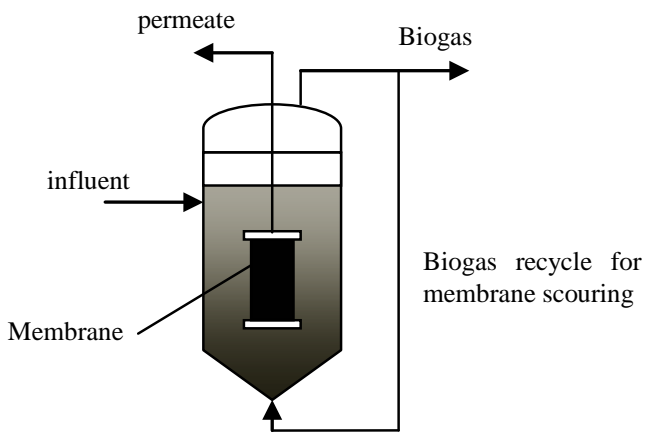

(a)

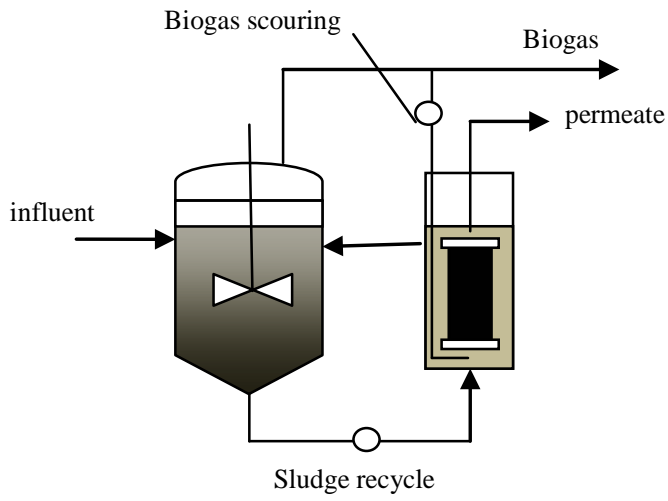

(b)

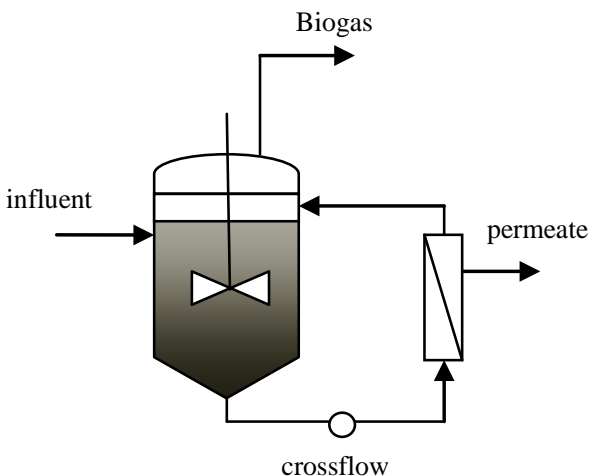

(c)

Figure 1. Different AnMBR system configurations. (a) Submerged membrane AnMBR; (b) AnMBR with external submerged hollow fiber membrane; (c) AnMBR with external crossflow membrane. bed (EGSB) [4], the fluidized anaerobic bed reactors [5], and other type of anaerobic reactors. The complete mix anaerobic bioreactor is a conventional anaerobic bioreactor. Without coupling with the membrane filtration, the complete mix bioreactor may only be suitable for the solid or sludge digestion or for the small-scale wastewater treatment because its low organic loading capacity could result in a large reactor volume for the treatment of a large wastewater flow, which becomes economically unfeasible. The UASB and EGSB can decouple the HRT from SRT through growing dense biomass to avoid the biomass wash-out under a short HRT condition, while the fluidized bed biofilm reactors through attached growth to retain the biomass in the bioreactor system. The current commercial high rate anaerobic bioreactor systems include Biothane UASB and EGSB, ADI hybrid bioreactor, $\mathrm{BioPaQ}^{\circledR} \mathrm{UASB}, \mathrm{PAQ}$ IC, etc. with the main market segments covering brewery, potato, pulp \& paper, dairy, vegetable, etc. [6]. According to Kassam et al. [6], the current commercial high rate anaerobic reactors have successfully treated high strength wastewaters with COD up to $60,000 \mathrm{mg} / \mathrm{L}$ and achieved a COD removal higher than $85 \%$ in a HRT range less than 5 days. The biogas production rates of commercial full-scale anaerobic systems are usually around $500 \mathrm{~L} / \mathrm{kg}$ COD. Integrating the high rate anaerobic bioreactors with the membrane filtration could further improve the effluent quality and operation stability.

One of the key components of an AnMBR system is the membrane filtration system. As shown in Figure 1, two different membrane filtration modules, the crossflow pressurised membrane modules and the submerged membrane filtration, can be used in AnMBRs: the external crossflow membrane filtration usually uses the conventional plate \& frame or the cylindrical hollow fiber cartridge configurations. In such system, the liquid crossflow is used to generate the surface shear to control the membrane fouling. The permeate flow is driven by the crossflow generated pressure or obtained by pump suction. The immersed or submerged membrane modules have been widely used in the aerobic membrane processes. The immersed membrane modules include the submerged flat sheet membrane modules and the submerged hollow fibre membrane modules. Figure 2(a) shows a schematic of the submerged flat sheet membrane panels which are usually arranged at a gap of around 8 to $12 \mathrm{~mm}$ with gas injected into these gaps to prevent the sludge accumulation and membrane fouling. For a fullscale module, up to 100 panels can be connected to a common manifold to form a filtration unit. Figure 2(b) shows a typical design of a submerged hollow fibre membrane module. The submerged hollow fibre membrane module consists of the module headers and fibre bundles. Most of the hollow fibre membranes used in 


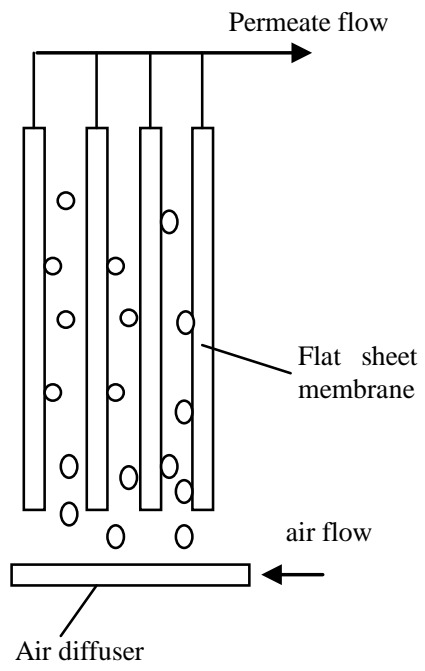

(a)

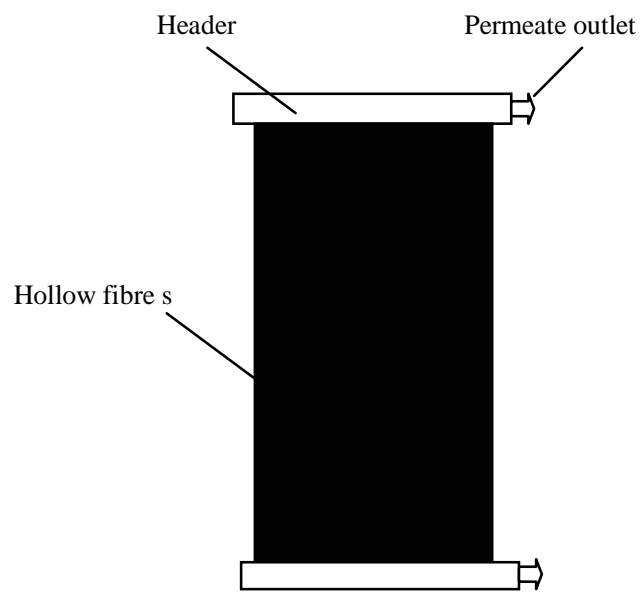

(b)

Figure 2. Schematics of submerged membrane modules. (a) Submerged flat sheet membrane modules; (b) Submerged d hollow fiber membrane modules.

MBRs are polyvinylidene fluoride (PVDF) hollow fibres with OD/ID range of $1-2 / 0.65-1(\mathrm{~mm} / \mathrm{mm})$ [7] and the fibre bundle can be packed into a curtain or cylindrical configuration. The current commercial submerged hollow fiber membrane modules can achieve a packing density around $160 \mathrm{~m}^{2} / \mathrm{m}^{3}$ tank volume, which can provide a total production capacity of $800 \mathrm{~m}^{3} /$ day at an average day design flux of $22 \mathrm{~L} / \mathrm{m}^{2} /$ day [8].

\section{Applications of AnMBRs in Wastewater Treatment}

AnMBRs have been tested for the treatment of a wide range of wastewaters and high solid content wastes, which include food processing wastewater, pulp and paper, landfill, municipal wastewater, etc. Table 1 summarises some reported results on the treatment of high strength wastewater of different sources by AnMBRs. In general, it has been showed that AnMBRs can achieve around $90 \%$ or higher COD removal and a methane production of 0.25 to $0.35 \mathrm{~m}^{3} \mathrm{CH}_{4} / \mathrm{kg}$ COD. The organic loadings of AnMBRs ranged from 5 to $30 \mathrm{~g}$ COD/L/day, MLSS concentration from 15 to $30 \mathrm{~g} / \mathrm{L}$ or higher, HRT from 1 to 25 days, and the membrane filtration flux from 5 to $10 \mathrm{LMH}$, were reported.

Recently, there is an increasing interest in the application of AnMBRs to municipal wastewater treatment [14-16]. Table 2 summarised some of the reported results on the applications of AnMBR in municipal wastewater treatment. Many studies showed that AnMBR can achieve efficient COD removal at temperature ranging from $20^{\circ} \mathrm{C}$ to $30^{\circ} \mathrm{C}$ in the treatment of municipal wastewater with a HRT from 24 to 6 hours tested. Most of studies showed that a long-term sustainable flux around 5 to $10 \mathrm{LMH}$ was achievable for the municipal wastewater treatment AnMBRs. Lin et al. [14] conducted a feasibility evaluation of submerged anaerobic membrane bioreactor for municipal secondary wastewater treatment. A cost analysis based on their lab-scale test showed that the operational cost of an AnMBR could be only 1/3 of the aerobic treatment process and the energy generated from

Table 1. Treatment performances and process conditions of AnMBR used in high strength wastewater treatment.

\begin{tabular}{|c|c|c|c|c|c|}
\hline & Anderson et al. [9] & Choo \& Lee [10] & Xie, et al. [11] & Van Zyl, et al. [12] & Zayen et al. [13] \\
\hline Wastewater & Brewery & Distillery & Kraft evaporator condensate & Coal industria WW & Landfill \\
\hline WW COD (g/L) & 80 to 90 & 22.6 & 10 & 19.1 & 41 \\
\hline Temperature $\left({ }^{\circ} \mathrm{C}\right)$ & 35 to 37 & 53 to 55 & 36 to 38 & 37 & 37 \\
\hline OLR (kg COD $/ \mathrm{m}^{3} /$ day) & Above 30 & 1.5 & 22.5 & Up to 25 & 6.27 \\
\hline HRT (day) & 2.5 to 4.2 & 15 & - & 1.3 & 7 \\
\hline MLSS concentration (g/L) & Up to 51 & - & 8 to 12 & 36 & - \\
\hline COD removal (\%) & $99 \%$ & $97 \%$ & $93 \%$ to $99 \%$ & $96.8 \%$ & $90.7 \%$ \\
\hline $\begin{array}{l}\text { Gas production } \\
\left(\mathrm{m}^{3} \mathrm{CH}_{4} / \mathrm{kgCOD}\right)\end{array}$ & 0.28 & 0.26 & 0.35 & - & 0.48 \\
\hline
\end{tabular}


Table 2. Treatment performances and process conditions of AnMBR used in low strength municipal wastewater treatment.

\begin{tabular}{|c|c|c|c|}
\hline & Lew, et al. [14] & Martinez-Sosa [15] & Lin, et al. [16] \\
\hline WW COD (g/L) & 0.54 & $0.6^{*}$ & $0.342-0.527$ (SCOD) \\
\hline Temperature $\left({ }^{\circ} \mathrm{C}\right)$ & 25 & 20 & 30 \\
\hline Reactor type & Complete mix & Complete mix & UASB \\
\hline Reactor volume $\left(\mathrm{m}^{3}\right)$ & 0.18 & 0.35 & 0.06 \\
\hline Membrane location & Side stream & Submerged & Submerged \\
\hline module type & Hollow fiber (dead end) & Flat-sheet & Flat sheet \\
\hline Membrane area $\left(\mathrm{M}^{2}\right)$ & 4 & 3.5 & 0.6 \\
\hline OLR (kg COD/m³/day) & $2.16^{*}$ & $0.4-0.9$ & 1 \\
\hline HRT (day) & 0.25 & $1.5-0.67$ & 0.42 \\
\hline COD removal & $88 \%$ & $84-94$ & 90 \\
\hline Gas yield $\left(\mathrm{m}^{3} \mathrm{CH}_{4} / \mathrm{kgCOD}\right)$ & - & 0.24 & 0.24 \\
\hline Membrane flux (LMH) & 7.5 & 7 & 12 \\
\hline
\end{tabular}

methane production can theoretically balance the energy required for the membrane biogas scouring [16]. Although it is feasible to treat municipal wastewater using AnMBR in terms of theoretical energy balance calculation, the full-scale commercial applications is still be limited by concerns of the stability of the treatment performance under ambient temperature; the effluent quality; and the energy recovery efficient under low influent COD conditions. The current experimental results showed that the temperature range for the effective anaerobic treatment of municipal wastewater is around $20^{\circ} \mathrm{C}$ to $30^{\circ} \mathrm{C}$, so the anaerobic treatment of municipal wastewater may be still a challenge for places with cold winter since it is not economic feasible to heat large amount of wastewater flow. Martinez-Sosa reported that the methane production reduced from $0.27 \mathrm{~L} / \mathrm{gCOD}$ to 0.24 $\mathrm{L} / \mathrm{gCOD}$ when the temperature is reduced from $35^{\circ} \mathrm{C}$ to $20^{\circ} \mathrm{C}$. Baek et al., [17], reported that no methane production was detected when treating municipal water with soluble COD ranging from 38 to $131 \mathrm{mg} / \mathrm{L}$ although $72 \%$ COD removal was observed. Dissolution of the methane in the treated effluent will also affect the energy recovery and increase the green house gas emission from the discharged effluent.

\section{Membrane Filtration Performance in AnMBR}

One of the key design and operation parameters of the membrane filtration is the operation flux, which directly affects the capital and operation costs of AnMBRs. The membrane process design flux determines the membrane surface area or the number of the membrane modules required to treat a certain wastewater flow. The number of the membrane modules installed will further affect the size of the membrane tank, piping, and the consumption of the chemicals used for the membrane cleaning. The design flux of AnMBRs, at which a stable operation is supposed to be attained, should be determined based on relatively long term testing. Some of the main observations on the membrane filtration operation in AnMBRs are summarised as below:

- Fluxes ranging from 6.7 to $10 \mathrm{LMH}$ were achievable for the treatment of the different wastewaters [18]. Based on the concept of the critical flux, controlling the operation flux is still the most critical strategies to achieve long-term stable operation.

- Intermittent permeation is important to achieve the long-term stable operation. The typical operation cycles could include 10 to 15 minutes permeation and 10 to 60 seconds relaxing. No obvious advantage of the membrane backwash over relaxing was observed.

- Many studies showed that the membrane filtration in AnMBRs could tolerate much higher suspended solid concentrations than the aerobic MBR systems, where the high MLSS concentration can considerably reduce the oxygen transfer efficiency, resulting in a drastic change in the filterability of the mixed liquor.

The membrane fouling is still the major factors limiting the efficiency of the AnMBR. For the sub-critical flux operation, rapid particle deposition on the membrane surface can be avoided and the membrane fouling is mainly caused by the graduate accumulation of colloidal or soluble SMP in the mixed liquor. Although many studies have showed that the SMPs mainly consist of protein and polysaccharides, little insights into the colloidal properties of the SMPs have been developed so far. 
Hence, the interaction mechanisms between the SMPs and the membrane surface are still unclear. In addition to the membrane fouling caused by the SMPs, the inorganic compounds can also play an important role in the membrane fouling in AnMBR. Herrera-Robledo et al. [19] reported that the cake layer was mainly composed of volatile solids (85\%) and the rest were related to mineral matter, with the presence of inorganic salts containing Ca, $\mathrm{Mg}, \mathrm{Fe}, \mathrm{P}$ and Si. Studies showed that metal complexation could play an important role in the development of the irreversible membrane fouling. Lyko et al. [20] demonstrated that a significant amount of extracellular polymeric substances (EPS) could be released by treating the fouled membrane samples with $\mathrm{Ca}^{2+}$ selective cation exchange resin (CER). Iron has also been detected on the fouled membrane surface. Choo and Lee [10] suggested that the precipitation of the struvite $\left(\mathrm{MgNH}_{4} \mathrm{PO}_{4} \cdot 6 \mathrm{H}_{2} \mathrm{O}\right)$ might play an important role in the inorganic membrane fouling in AnMBRs.

The main strategies to control membrane fouling in AnMBR include the crossflow for the external membrane filtration and the biogas scouring for the submerged membrane filtration system. The membrane gas scouring technology has been well developed through the aerobic MBR development. The energy efficient membrane filtration gas scouring technologies include intermittent gas scouring [8] and, recently, the pulse gas scouring [21]. Other techniques tested for the membrane fouling control include using ultrasonic techniques [22], vibrating membranes [23], and adding chemicals or adsorbents, such as powder activated carbon, to improve the filterability of the mixed liquor or reduce the concentration of the soluble membrane foulants [24]. Recently, Kim et al. [5] tested directly immersing the hollow fiber membrane in a fluidized granular activated carbon (GAC) anaerobic biofilm reactor and reported that the fluidized GAC particle could be utilized for the membrane fouling control.

\section{Conclusion}

AnMBR concept was developed about three decades ago, but its commercial applications have been largely limited by the efficiency of the membrane filtration. Recent development in the large-scale wastewater treatment MBR has largely increased the potential of the anaerobic membrane technology as a practical, advanced full-scale wastewater treatment technology. The current research demonstrated that the AnMBR technology can be used for the treatment of a wide range of wastewaters with a great potential to recover energy and resources from both high strength wastewaters.

\section{REFERENCES}

[1] B. Q. Liao, J. T. Kraemer and D. M. Bagley, “Anaerobic
Membrane Bioreactors: Applications and Research Directions," Critical Review in Environmental Science and Technology, Vol. 36, No. 6, 2006, pp. 489-530. http://dx.doi.org/10.1080/10643380600678146

[2] D. Martinez-Sosa, B. Helmreich, T. Netter, S. Paris, F. Bischof and H. Horn, "Anaerobic Submerged Membrane Bioreactor (AnSMBR) for Municipal Wastewater Treatment under Mesophilic and Psychrophilic Temperature Conditions,” Bioresource Technology, Vol. 102, No. 22, pp. 10377-10385. http://dx.doi.org/10.1016/j.biortech.2011.09.012

[3] M. L. Salazar-Pelaez, J. M. Morgan-Sagastume and A. Noyola, "Influence of Hydraulic Retention Time on Fouling in a UASB Coupled with an External Ultrafiltration Membrane Treating Synthetic Municipal Wastewater," Desalination, Vol. 277, No. 1, 2011, pp. 164-170. http://dx.doi.org/10.1016/j.biortech.2011.09.012

[4] L. B. Chu, F. L. Yang and F. L. Zhang, "Anaerobic Treatment of Domestic Wastewater in a Membrane-Coupled Expended Granular Sludge Bed (EGSB) Reactor under Moderate to Low Temperature,” Process Biochemistry, Vol. 40, No. 3, 2005, pp. 1063-1070. http://dx.doi.org/10.1016/j.procbio.2004.03.010

[5] J. Kim, K. Kim, H. Young, H. Ye, E. Lee, C. Shin, P. Mccarty and J. Bae, “Anaerobic Fluidized Bed Membrane Bioreactor for Wastewater Treatment,” Environmental Science \& Technology Letters, Vol. 45, No. 17, 2011, pp. 576-581.

[6] Z. A. Kassam, L. Yerushalmi and S. Guiot, "A Market Study on the Anaerobic Wastewater Treatment Systems," Water, Air, and Soil Pollution, Vol. 143, No. 1-4, 2003, pp. 179-192. http://dx.doi.org/10.1023/A:1022807416773

[7] S. Chang, "Application of Submerged Hollow Fibre Membrane in Membrane Bioreactors: Filtration Principles, Operation, and Membrane Fouling," Desalination, Vol. 283, 2011, pp. 31-39.

http://dx.doi.org/10.1016/j.desal.2011.03.025

[8] T. Bure and J. Cumin, "MBR Module Design and Operation,” Desalination, Vol. 250, No. 3, 2010, pp. 10731077. http://dx.doi.org/10.1016/j.desal.2009.09.111

[9] G. K. Anderson, B. Kasapgil and O. Ince, "Microbial Kinetics of a Membrane Anaerobic Reactor," Environmental Technology, Vol. 17, No. 5, 1996, p. 449. http://dx.doi.org/10.1080/09593331708616407

[10] K. H. Choo and C. H. Lee, "Membrane Fouling Mechanisms in the Membrane-Coupled Anaerobic Bioreactor," Water Research, Vol. 30, No. 8, 1996, pp. 1771-1780. http://dx.doi.org/10.1016/0043-1354(96)00053-X

[11] K. Xie, H. J. Lin, B. Mahendran, D. M. Bagle, K. T. Leung, S. N. Liss and B. Q. Liao, "Performance and Fouling Characteristics of a Subme Rged Anaerobic Membrane Bioreactor for Kraft Evaporator Condensate Treatment,” Environmental Technology, Vol. 31, No. 5, 2010, pp. 511-521.

http://dx.doi.org/10.1080/09593330903527898

[12] P. J. Van Zyl, M. C. Wentzel, G. A. Ekama and K. J. Riedel, "Design and Start-Up of a High Rate Anaerobic Membrane Bioreactor for the Treatment of a Low $\mathrm{pH}$, High Strength, Dissolved Organic Waste Water,” Water 
Science Technology, Vol. 57, No. 2, 2008, pp. 291-295. http://dx.doi.org/10.2166/wst.2008.083

[13] A. Zayen, S. Mnif, F. Aloui, F. Fki, S. Loukil, M. Bouaziz and S. Sayadi, “Anaerobic Membrane Bioreactor for the Treatment of Leachates from Jebel Chakir Discharge in Tunisia,” Journal of Hazardous Materials, Vol. 177, No. 1-3, 2010, pp. 918-923. http://dx.doi.org/10.1016/j.jhazmat.2010.01.004

[14] B. Lew, S. Tarre, M. Beliavski, C. Dosoretz and M. Green, "Anaerobic Membrane Bioreactor (AnMBR) for Domestic Wastewater Treatment,” Desalination, Vol. 243, No. 1-3, 2009, pp. 251-257. http://dx.doi.org/10.1016/j.desal.2008.04.027

[15] D. Martinez-Sosa, B. Helmreich, T. Netter, S. Paris and F. bischof, “Anaerobic Submerged Membrane Bioreactor (AnSMBR) for Municipal Wastewater Treatment under Mesophilic and Psychrophilic Temperature Conditions," Bioresource Technology, Vol. 102, No. 22, 2011, pp. 10377-10385. http://dx.doi.org/10.1016/j.biortech.2011.09.012

[16] H. Lin, J. Chen, F. Wang, L. Ding and H. Hong, "Feasibility Evaluation of Submerged Anaerobic Membrane Bioreactor for Municipal Secondary Wastewater Treatment," Desalination, Vol. 280, 2011, pp. 120-126. http://dx.doi.org/10.1016/j.desal.2011.06.058

[17] S. H. Baek, K. R. Pagilla and H. J. Kim, "Lab-Scale Study of an Anaerobic Membrane Bioreactor (AnMBR) for Dilute Municipal Wastewater Treatment," Biotechnology and Bioprocess Engineering, Vol. 15, No. 4, 2010, pp. 704-708. http://dx.doi.org/10.1007/s12257-009-0194-9

[18] S. Kirmura, “Japans Aqua Renaissance'90 Project,” Water Science \& Technology, Vol. 23, No. 7-9, 1991, pp. 1573-1592.
[19] H. Herrera-Robledo, J. M. Morgan-Sagastume and A. Noyola, "Biofouling and Pollutant Removal during LongTerm Operation of an Anaerobic Membrane Bioreactor Treating Municipal Wastewater,” Biofouling, Vol. 26, No. 1, 2010, pp. 23-30. http://dx.doi.org/10.1080/08927010903243923

[20] S. Lyko, D. Al-Halbouni, T. Wintgens, A. Janot, J. Hollender, W. Dott and T. Melin, "Polymeric Compounds in Activated Sludge Supernatant-Characterisation and Retention Mechanisms at a Full-Scale Municipal Membrane Bioreactor,” Water Research, Vol. 41, No. 17, 2007, pp. 3894-3902.

http://dx.doi.org/10.1016/j.watres.2007.06.012

[21] M. Kondo, J. Cumin, Y. Hong, R. Bayly, M. Gao and R. Rubin, "Reexamination of the Gas Sparging Mechanism for Membrane Fouling Control," Proceedings of the Water Environment Federation, WEFTEC 2010, New Orleans, pp. 6986-7007.

[22] P. Sui, X. Wen and X. Huang, "Feasibility of Employing Ultrasound for On-Line Membrane, Fouling Control in an Anaerobic Membrane Bioreactor,” Desalination, Vol. 219, No. 1, 2008, pp. 203-213. http://dx.doi.org/10.1016/j.desal.2007.02.034

[23] A. Kola, Y. Ye, A. Ho, P. Le-Clech and V. Chen, “Application of Low Frequency Transverse Vibration on Fouling Limitation in Submerged Hollow Fibre Membranes," Journal of Membrane Science, Vol. 409-410, 2012, pp. 54-65. http://dx.doi.org/10.1016/j.memsci.2012.03.017

[24] H. Park, K. H. Choo and C. H. Lee, "Flux Enhancement with Powder Activated Carbon Addition in the Membrane Anaerobic Bioreactor," Separation Science and Technology, Vol. 34, No. 14, 1999, pp. 2781-2792. http://dx.doi.org/10.1081/SS-100100804 